\title{
The development and characterisation of porphyrin isothiocyanate-monoclonal antibody conjugates for photoimmunotherapy
}

\author{
R Hudson', M Carcenac', K Smith³, L Madden², OJ Clarke', A Pèlegrin'2, J Greenman³ and RW Boyle*,I \\ 'Department of Chemistry, Clinical Biosciences Institute, University of Hull, Cottingham Road, Hull, East Yorkshire HU6 7RX, UK; ${ }^{2}$ CRLC Val d'Aurelle- \\ Paul Lamarque, Montpellier, France; ${ }^{3}$ Postgraduate Medical School, Clinical Biosciences Institute, University of Hull, Cottingham Road, Hull, East Yorkshire \\ HU6 7RX, UK
}

\begin{abstract}
A promising approach to increase the specificity of photosensitisers used in photodynamic therapy has been through conjugation to monoclonal antibodies (MAb) directed against tumour-associated antigens. Many of the conjugations performed to date have relied on the activated ester method, which can lead to impure conjugate preparations and antibody crosslinking. Here, we report the development of photosensitiser-MAb conjugates utilising two porphyrin isothiocyanates. The presence of a single reactive isothiocyanate allowed facile conjugation to MAb FSP 77 and 17.I A directed against internalising antigens, and MAb 35A7 that binds to a non-internalising antigen. The photosensitiser-MAb conjugates substituted with I $-3 \mathrm{~mol}$ of photosensitiser were characterised in vitro. No appreciable loss of immunoreactivity was observed and binding specificity was comparable to that of the unconjugated MAb. Substitution with photosensitiser had a minimal effect on antibody biodistribution in vivo for the majority of the conjugates, although a decreased serum half-life was observed using a cationic photosensitiser at the higher loading ratios. Tumour-to-normal tissue ratios as high as 33.5 were observed using MAb 35A7 conjugates. The internalising conjugate showed a higher level of phototoxicity as compared with the non-internalising reagent, using a cell line engineered to express both target antigens. These data demonstrate the applicability of the isothiocyanate group for the development of high-quality conjugates, and the use of internalising MAb to significantly increase the photodynamic efficiency of conjugates during photoimmunotherapy.
\end{abstract}

British Journal of Cancer (2005) 92, |442-|449. doi:I0.1038/sj.bjc.66025 I7 www.bjcancer.com

Published online 5 April 2005

(C) 2005 Cancer Research UK

Keywords: photodynamic therapy; monoclonal antibodies; bioconjugation

Photodynamic therapy (PDT) is a multicomponent anticancer treatment that involves the administration of a photosensitising drug and its subsequent activation by light of the appropriate wavelength (Macdonald and Dougherty, 2001). In the field of oncology, PDT is primarily used for the treatment of superficially localised tumours (Dougherty et al, 1998). In this context, the area illuminated is accessible, and treatment is associated with minimal toxicity, favourable tumour response and a good cosmetic outcome (Kubler et al, 1999). Photodynamic therapy has also been investigated for the treatment of deep-seated or disseminated malignancies (Biel, 1998); unfortunately, acute damage to surrounding normal tissue and treatment-related toxicity is often observed as a consequence of poor photosensitiser selectivity, and difficulties directing the light source to the tumour mass (Nseyo et al, 1998).

Several approaches have been investigated to increase the specificity of photosensitisers for cancerous tissues (Brasseur et al, 1999; Gijsens et al, 2000; Swamy et al, 2002). Of considerable interest has been the conjugation of photosensitisers to monoclonal antibodies (MAb) directed against tumour-associated antigens; this approach is often termed photoimmunotherapy

*Correspondence: Dr RW Boyle; E-mail: R.W.Boyle@hull.ac.uk Revised 17 February 2005; accepted 21 February 2005; published online 5 April 2005
(PIT). Conjugates of photosensitisers with MAb directed against a variety of targets have been produced including oncofoetal antigens (Carcenac et al, 1999), receptors for signal transduction pathways (Carcenac et al, 2001) and growth factor receptors (Hamblin et al, 2000).

A notable drawback in the development of well-characterised photosensitiser-MAb conjugates is the efficient conjugation of the photosensitiser to the antibody. The majority of current strategies for conjugation involve the use of photosensitisers bearing an activated ester functionality for conjugation to free amines within the MAb structure (Vrouenraets et al, 1999). Typically, photosensitisers in clinical trials are used. A limitation in such syntheses is the isolation of photosensitisers containing only one activated ester. Previously a derivative of meta-tetrahydroxyphenyl chlorin ( $m$-THPC) has been synthesised bearing four activated esters on the meta positions of the meso phenyl rings. The monoesterified compound was then accessed through hydrolysis of this intermediate. However, the kinetics of the reaction are difficult to control and appreciable amounts of the fully hydrolysed and therefore unreactive photosensitiser are generated, as well as photosensitiser bearing two reactive esters (Vrouenraets et al, 1999). These impurities affect the stoichiometry of further reactions, and multiple reactive sites can cause antibody crosslinking during conjugation, leading to reduced yields and increasing aggregate formation, which can lead to nonspecific 
uptake. Alternatively, syntheses describing the activation of the carboxyl groups of monoaspartyl chlorin e6 (Npe6), often in conjunction with the use of polymeric carrier molecules, have been reported (Goff et al, 1991; Hamblin et al, 1996). The MAb and photosensitiser are attached to the carrier molecule, which usually acts to increase both photosensitiser loading and conjugate solubility. The photosensitiser is often used without purification and contains three carboxyl groups that may be functionalised, which could lead to crosslinking of the antibody or polymer. The use of a polymeric carrier may also affect the photophysics of the photosensitiser and can lead to nonspecific uptake.

In consideration of the above limitations, we have recently developed a series of porphyrin photosensitisers bearing a single reactive isothiocyanate group for conjugation to biomolecules (Clarke and Boyle, 1999; Sutton et al, 2002). Facile conjugation to bovine serum albumin was demonstrated with minimal nonspecific binding (Sutton et al, 2002). We now report the use of photosensitiser isothiocyanates for conjugation to MAb. The previously developed photosensitisers were conjugated to $\mathrm{MAb}$ 35A7, FSP 77 and 17.1A. Monoclonal antibody 35A7 recognises and binds to carcinoembryonic antigen (CEA), which is overexpressed on colon adenocarcinomas and represents an antigen that is not internalised upon MAb binding. FSP 77 binds to the extracellular domain of the erb-B2 receptor, a receptor widely expressed on breast and ovarian cancers. The EpCAM epithelial antigen, to which MAb 17.1A binds, is upregulated in a variety of malignancies including colorectal carcinoma. FSP 77 and $17.1 \mathrm{~A}$ are internalised following antigen binding. The conjugates were characterised in vitro and in vivo, and their potential for use in PIT in vitro was assessed using the SKOv3-CEA-1B9 cell line, which has been previously engineered to express both the CEA and erb-B2 antigens (Carcenac et al, 2001). Using this, we were able to compare directly the efficacy of the internalising conjugates with those that remain surface bound.

These data highlight the versatility of the isothiocyanate group, which allows conjugation to MAb without the generation of multiple reactive sites or in situ reactive intermediates. The enhanced cell killing efficiency of the internalising conjugates is also demonstrated, suggesting that such molecules should be the focus of future PIT studies.

\section{MATERIALS AND METHODS}

\section{Photosensitisers}

The two water-soluble photosensitisers 5-(4-isothiocyanatophenyl)-10,15,20-tri-(3,5-dihydroxyphenyl)porphyrin (1) and 5-(4- isothiocyantophenyl)-10,15,20-tris-(4- $N$-methylpyridiniumyl)porphyrin trichloride (2) (Figure 1) were synthesised as described previously (Sutton et al, 2002). Briefly, condensation of 4acetamidobenzaldehyde with either 3, 5-dimethoxybenzaldehyde or pyridine 4-carboxaldehyde under Adler-Longo conditions gave the corresponding monoacetamido porphyrins, following chromatographic separation. Subsequent acid hydrolysis yielded the analogous monoamino derivatives. Demethylation of the methoxy functionalities of porphyrin 1 using boron tribromide gave the hexa-hydroxylated analogue, which was subsequently treated with $1,1^{\prime}$-thiocarbonyldi-2, 2'-pyridone (TDP) to yield the isothiocyanate. Porphyrin 2 was reacted with TDP to generate the isothiocyanate functionality prior to quaternisation with methyl iodide and anion exchange. The photosensitisers were rigorously purified following each synthetic step and stored at $-20^{\circ} \mathrm{C}$ under a nitrogen atmosphere until further use.

\section{Monoclonal antibodies}

The murine MAb 35A7 and FSP 77 (both IgG1) have been used previously for conjugation to tetrasulphonato aluminium phthalocyanine using the in situ generation of an active ester (Carcenac et al, 1999). MAb 35A7 binds to an epitope on CEA, which is overexpressed on foetal colon and colon adenocarcinomas (Khare et al, 2001). MAb FSP 77 binds to the extracellular domain of the erb-B2 receptor; this antigen is overexpressed on breast and ovarian cancers (Cuello et al, 2001). The MAb 17.1A (IgG2a; a generous gift from Professor S. Warnaar) is an anti-EpCAM antibody that has also been used previously as the targeting component of a photosensitiser immunoconjugate, which recognises a commonly overexpressed antigen on colorectal cancers that is internalised on binding (Hamblin et al, 2000).

\section{Radiolabelling and preparation of conjugates}

The intact MAb 35A7 and FSP 77 were radioiodinated using the Iodogen method (1, 3, 4, 6-tetrachloro- $3 \alpha, 6 \alpha$-diphenylglycoluryl, Sigma, Poole, UK) to arrive at a final specific activity of $0.1 \mu \mathrm{Ci}$ of ${ }^{125} \mathrm{I}$ or $1 \mu \mathrm{Ci}{ }^{131} \mathrm{I}$ per $\mu \mathrm{g}$ of protein $(1 \mu \mathrm{Ci}=37 \mathrm{kBq})$. Free radioiodine was separated from the MAb on a Sephadex G25 column (Amersham Biosciences, Uppsala, Sweden) eluting with $0.5 \mathrm{M}$ sodium bicarbonate buffer ( $\mathrm{pH} 9.2$ ).

To a $1 \mathrm{ml}$ solution of MAb, at a concentration of $1 \mathrm{mg} \mathrm{ml}^{-1}$ in $0.5 \mathrm{~m}$ bicarbonate buffer ( $\mathrm{pH} 9.2$ ), was added photosensitiser (PS) 1 in DMSO $(50 \mu \mathrm{l})$ or PS 2 in $\mathrm{H}_{2} \mathrm{O}(50 \mu \mathrm{l})$. The photosensitisers were added separately at varying concentrations of either 20,40 or $60 \mathrm{~mol}$ of photosensitiser per mole of MAb. The reaction vessels<smiles>CS(=O)(=S)c1ccc(-c2cc(=C(c3cc(O)cc(O)c3)c3cc(O)cc(O)c3)ccc3nc4cc(O)cc(O)cc(ccc5nc6cc(O)cc(O)cc(ccc7c(c8nc2C=C8)N=7)c56)c34)cc1</smiles>

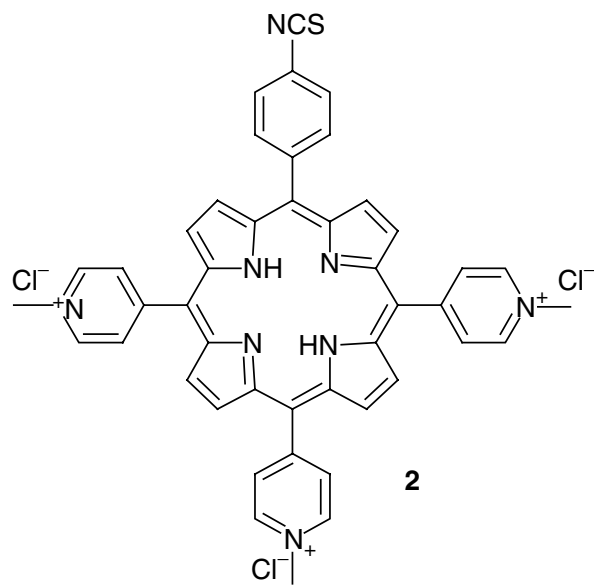

Figure I Chemical structure of porphyrin isothiocyanates. 
were agitated gently at room temperature for $1 \mathrm{~h}$ and protected from light. The conjugates were purified using Sephadex G25 columns (Amersham Biosciences, Uppsala, Sweden) equilibrated and eluted with PBS. The number of moles of photosensitiser conjugated per mole of antibody (degree of labelling, DOL) was calculated by spectroscopy. Briefly, the number of moles of photosensitiser per conjugate was calculated thus: $C_{\text {photosensitiser }}=A_{420 \mathrm{~nm}} / \varepsilon$. The MAb concentration $\left(\mathrm{mg} \mathrm{ml}^{-1}\right)$ was calculated using: $\mathrm{MAb}$ conc $\left(\mathrm{mg} \mathrm{ml}^{-1}\right)=A_{280 \mathrm{~nm}} / 1.3$. This then allowed calculation of the number of moles of MAb per conjugate. The DOL was derived for each conjugate at all the initial molar ratios employed by division of the moles of photosensitiser by the moles of MAb.

\section{Cell lines}

The LS174T human colon carcinoma cell line to which MAb 35A7 binds, SKOv3 human ovarian carcinoma cell line that MAb FSP 77 binds to and the hybrid cell line SKOv3-CEA-1B9 were available in our laboratories. The cell lines were grown under standard culture conditions. Cell lines were grown as monolayers at $37^{\circ} \mathrm{C}$ in an environment containing 5\% $\mathrm{CO}_{2}$ in RPMI 1640 (Roswell Park Memorial Institute). This culture medium was supplemented with $10 \%\left(\mathrm{v} \mathrm{v}^{-1}\right)$ foetal calf serum (FCS), $2 \mathrm{mM} \mathrm{L}$-glutamine, $100 \mu \mathrm{g} \mathrm{ml}^{-1}$ streptomycin, $100 \mu \mathrm{g} \mathrm{ml}^{-1}$ penicillin and $0.25 \mu \mathrm{g} \mathrm{ml}^{-1}$ amphotericin B (Gibco, Paisley, UK). Cells were subcultured regularly to ensure exponential growth. The human colorectal adenocarcinoma cell line Colo 320 (European Collection of Animal and Cell Cultures) was used in studies involving MAb 17.1A. The cells were grown in RPMI supplemented with $10 \%\left(\mathrm{vv}^{-1}\right) \mathrm{FCS}, 2 \mathrm{nM} \mathrm{L}$ glutamine, $100 \mu \mathrm{g} \mathrm{ml}^{-1}$ streptomycin and $100 \mu \mathrm{g} \mathrm{ml}^{-1}$ penicillin.

\section{Animals and tumour model}

For experiments involving MAb 35A7, the human colon carcinoma cell line LS174T was implanted subcutaneously into the hind legs of Swiss nude mice (CRLC, Montpellier, France). SKOv3 cells were injected subcutaneously into the same animal model for studies using the MAb FSP 77. Mice were maintained and handled in accordance with the recommendations of the local animal care committee. The animals were allowed free access to food and water. All the in vivo experiments were performed in compliance with the French guidelines for experimental animal studies (Agreement No. B 34-172-27) and fulfil the UKCCCR guidelines for the welfare of animals in experimental neoplasia.

\section{Flow cytometry}

Cells were removed from culture flasks with $5 \mathrm{~mm}$ EDTA in PBS. After washing cells were counted, resuspended in PBS $/ 0.25 \%$ $\left(\mathrm{w} \mathrm{v}^{-1}\right) \mathrm{BSA}$ and $2 \times 10^{5}$ cells were added to each tube. The cells were labelled with $50 \mu \mathrm{l}\left(5 \mu \mathrm{g} \mathrm{ml}^{-1}\right)$ of primary antibody (conjugated/unconjugated/irrelevant) for $1 \mathrm{~h}$ at $4{ }^{\circ} \mathrm{C}$. After washing with PBS/0.25\% ( $\left.\mathrm{w} \mathrm{v}^{-1}\right)$ BSA, cells were labelled with $50 \mu \mathrm{l}\left(10 \mu \mathrm{g} \mathrm{ml}^{-1}\right)$ of rabbit anti-mouse IgG-FITC (Serotec, Oxford, UK) for $1 \mathrm{~h}$ at $4{ }^{\circ} \mathrm{C}$. A further wash with $\mathrm{PBS} / 0.25 \%\left(\mathrm{w} \mathrm{v}^{-1}\right) \mathrm{BSA}$ was performed before analysis of cells on a FACSCalibur flow cytometer (BD Biosciences, Oxford, UK).

\section{In vitro phototoxicity}

This procedure was employed for analysis of the cytotoxicity of the conjugates of MAb 35A7 and FSP 77 using the SKOv3-CEA-1B9 cell line, and the conjugates of MAb 17.1A using the Colo 320 cell line. Cells in logarithmic growth phase were harvested and their

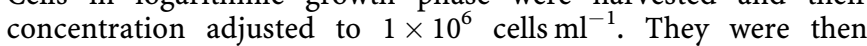
incubated for $24 \mathrm{~h}$ in the dark with photosensitiser or conjugate at varying concentrations in the absence of serum. Following incubation, the cells were washed with DMEM (to eliminate unbound photosensitiser), resuspended and plated (8000 cells well $^{-1}$ ) in quadruplicate into a 96-well plate. The plate was then irradiated with $10 \mathrm{~J} \mathrm{~cm}^{-2}$ of cooled and filtered red light $(630 \mathrm{~nm})$ delivered by a Patterson light system (Phototherapeutics Ltd, Albringham, UK: Patterson Lamp BL1000A, bandpass $630 \pm 15 \mathrm{~nm}$ filter). After irradiation, $5 \mu \mathrm{l}$ of FCS was added to each well and the plates (both irradiated and non-irradiated as a dark toxicity control) were incubated overnight.

The tetrazolium salt 3-4, 5-dimethylthiazol-2-yl)-2, 5-diphenyltetrazolium bromide (MTT) assay was performed $18-24 \mathrm{~h}$ postirradiation. Briefly, $10 \mu \mathrm{l}$ of MTT solution $\left(5 \mathrm{mg} \mathrm{ml}^{-1}\right.$ PBS, MTT Thiazoyl blue, Sigma Cat. No. M-5655) was added to each well. The plates were then returned to the incubator for $4 \mathrm{~h}$ or until sufficient colour developed. When this was accomplished, $150 \mu \mathrm{l}$ of isopropanol-HCl $(0.04 \mathrm{~N})$ was added to each well to stop the reaction. The cells were lysed mechanically, and the blue formazan crystals produced by the mitochondria of living cells were dissolved by vigorous pipetting. The plates were then read at $570 \mathrm{~nm}$ using a Bio-Tek Elx 800 plate reader. The percentage of cell survival was calculated in proportion to the number of cells incubated without photosensitiser.

\section{In vitro binding}

To measure the in vitro binding and nonspecific binding of the radiolabelled conjugates of MAb 35A7 and FSP 77, purified antigen (CEA or erb-B2) was used immobilised on sepharose. The procedure was performed in quadruplicate. An irrelevant sepharose-bound antigen $(\mathrm{Px})$ was used to assay any non-specific antigen binding of the conjugates. Consequently, $1 \mu \mathrm{g}$ of purified sepharose-bound antigen was added per tube. A control tube containing sepharose without antigen was used in each experiment to assay any non-specific binding to the sepharose alone. To each of these tubes was added $20 \mathrm{ng}$ of either conjugate or unconjugated antibody as a $200 \mu \mathrm{l}$ solution of BSA-PBS buffer containing $1 \%$ $\left(\mathrm{vv}^{-1}\right)$ normal mouse serum. The total radioactivity of each tube was measured for $1 \mathrm{~min}$. The tubes were then incubated overnight at room temperature with gentle agitation. After incubation, the tubes were washed with $2 \mathrm{ml} \mathrm{BSA-PBS}\left(1 \mathrm{mg} \mathrm{ml}^{-1}\right)$ and centrifuged for $5 \mathrm{~min}$ at 3000 r.p.m. The supernatant was removed by aspiration and the washing procedure repeated. Once complete, the radioactivity of the tubes was again measured for $1 \mathrm{~min}$. The percentage in vitro binding or nonspecific binding was calculated using the following equation: percentage binding $=(\gamma$ after incubation $/ \gamma$ before incubation) $\times 100$.

\section{In vivo biodistribution}

Biodistribution studies were performed in Swiss nude mice bearing subcutaneously implanted xenograft (LS174T and SKOv3). At $24 \mathrm{~h}$ before injection, $0.5 \mathrm{ml}$ of pure Lugol's iodine solution was added to the drinking water to block the thyroid glands of the mice. A mixture of ${ }^{125} \mathrm{I}$ (conjugates) and ${ }^{131} \mathrm{I}$ (unconjugated $\mathrm{Mab}$ ) (each at a specific radioactivity of $1 \mu \mathrm{Ci} / 10 \mu \mathrm{g} \mathrm{MAb}$ ) was intravenously injected into three mice per group when the tumours had reached a diameter of 3-5 mm. At $24 \mathrm{~h}$ after injection, the mice were killed by $\mathrm{CO}_{2}$ inhalation. Each mouse was dissected and the organs, body parts and blood placed in separate preweighed tubes. All the tubes were weighed separately before and after the addition of the body parts and the difference between empty and filled tubes calculated. The ${ }^{125} \mathrm{I}$ and ${ }^{131} \mathrm{I}$ radioactivities of each tube were measured in a dual-channel scintillation counter (Cobra II auto-gamma, Packard). ${ }^{131}$ I activity (14\%) was subtracted from ${ }^{125}$ I radioactivity to compensate for overlap of ${ }^{131} \mathrm{I}-\gamma$-rays in the ${ }^{125} \mathrm{I}$ window. Radioactivity levels are expressed as the percent of injected dose per gram of tissue $\left(\% \mathrm{ID} \mathrm{g}^{-1}\right)$. The tumour-to-normal tissue ratios were also calculated. 


\section{RESULTS}

\section{Conjugation and flow cytometric analysis of conjugate binding}

The two photosensitisers were conjugated to MAb 35A7, FSP 77 and $17.1 \mathrm{~A}$ as described, using an initial molar ratio of 20 . The purified conjugates had a DOL between 1.5 and 2.0. Following conjugation, the reactivity of the $\mathrm{MAb}$ - porphyrin conjugates was compared to that of the unconjugated MAb using the appropriate antigen-positive cell lines by flow cytometry (Figure 2).

The binding of the conjugates prepared using MAb 35A7 and FSP 77 were analysed using the SKOv3-CEA-1B9 cell line. This cell line had originally been engineered from the erb-B2-expressing cell line SKOv3 to simultaneously express CEA as well as erb-B2 (Carcenac et al, 2001). The conjugates prepared using MAb 17.1A were evaluated using the Colo 320 cell line. The conjugate binding (dotted lines) to the respective cell lines is comparable to that of the unconjugated MAb (dashed lines) for each MAb and cell line employed. Conjugating PS 1 and PS 2 to MAb 35A7 and FSP 77 resulted in slightly diminished binding to the SKOv3-CEA-1B9 cell line (top four histograms), although the conjugates displayed positive binding with respect to the irrelevant control. The FSP 77 -PS 1 conjugate displayed a more pronounced loss of binding, although it was still positive with respect to the control. No apparent loss of binding was observed using the conjugates of MAb 17.1A on Colo 320 cells.

\section{In vitro cytotoxicity}

The photocytotoxicity of the photosensitisers and conjugates was assayed by the MTT assay using the SKOv3-CEA-1B9 cell line
(35A7 and FSP 77) and the Colo 320 cell line (17.1A). Use of SKOv3-CEA-1B9 cells allowed direct comparison between internalising and non-internalising conjugates on the same cell line. The $\mathrm{IC}_{50}$ values for the photosensitisers and conjugates were measured to allow for comparative assessment of the effects of $\mathrm{MAb}$ conjugation on phototoxicity and are presented in Tables 1 and 2. The photosensitisers and conjugates were not toxic to the cell lines in the absence of light (data not shown).

The PS 1-17.1A conjugate caused almost five times more cell growth inhibition than the free photosensitiser. However, coupling PS 2 to the MAb inhibited cell growth by $90 \%$ at a concentration of only $2.2 \mu \mathrm{M}$, in comparison to the free photosensitiser, which required $29.0 \mu \mathrm{M}$ to cause just $50 \%$ cell growth inhibition. The noninternalising PS 1-35A7 conjugate was less effective against the SKOv3-CEA-1B9 cell line than the free photosensitiser. In contrast, the internalising PS 1 -FSP 77 conjugate gave an $\mathrm{IC}_{50}$ value 15 -fold less than that of the free photosensitiser. A similar trend is observed with the conjugates of PS 2 , although both the conjugates in this case were more phototoxic than the unconjugated photosensitiser. Again, the internalising PS 2-FSP 77 conjugate led to greater cell growth inhibition, having an $\mathrm{IC}_{50}$ value five-fold lower than the non-internalising conjugate and 14 times less than the free photosensitiser. Overall, conjugating the photosensitisers to $\mathrm{MAb}$ increases their potential for PIT in vitro, although internalising conjugates are clearly the most efficient.

\section{Increased loading ratios and in vitro antigen binding}

Having established a protocol for conjugating photosensitiser isothiocyanates to MAb, demonstrated retention of MAb binding by FACS and enhanced photodynamic efficiency in vitro, the effect
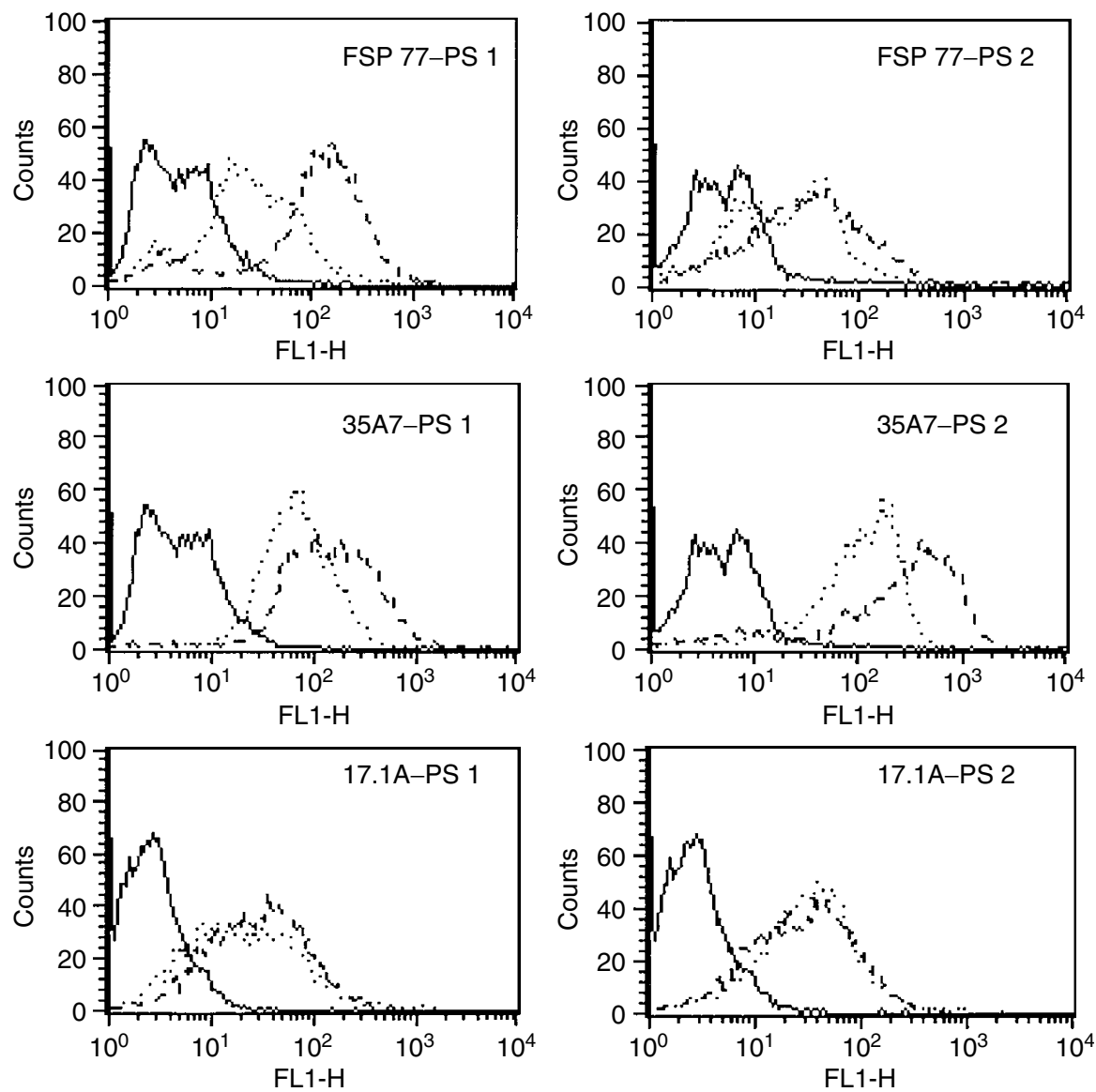

Figure 2 Indirect flow cytometric analysis of conjugate binding (bold, irrelevant control; dashed, unconjugated MAb; dotted, porphyrin conjugates). 
Table I $\quad C_{50}$ values $(\mu \mathrm{M})$ for the free PS $\mathbf{I}$ and PS $\mathbf{2}$ and MAb-17.IA conjugates to the Colo 320 cell line

\begin{tabular}{lc}
\hline & IC $\mathbf{5 0}$ value \\
\hline PS I & $11.5 \pm 2.1$ \\
PS I -I7.IA & $2.50^{\mathrm{a}}$ \\
PS 2 & $29.0 \pm 4.2$ \\
PS $\mathbf{2}-17.1 \mathrm{~A}$ & $2.2^{\mathrm{a}, \mathrm{b}}$ \\
\hline
\end{tabular}

$\mathrm{MAb}=$ monoclonal antibodies; $\mathrm{PS}=$ photosensitisers. Values expressed as the mean \pm s.d. of three experiments. ${ }^{a}$ S.d. could not be determined in these cases due to the limited availability of MAb I7.IA. ${ }^{b} \mathrm{LD}_{90}$ value.

Table $\mathbf{2} I C_{50}$ values $(\mu \mathrm{M})$ for the free PS $\mathbf{I}$ and PS $\mathbf{2}$ and MAb conjugates to the SKOv3-CEA-IB9 cell line

\begin{tabular}{lc}
\hline & IC $\mathbf{5 0}$ value \\
\hline PS I & $68.0 \pm 18.0$ \\
PS I -35A7 & $N o I C_{50}$ \\
PS I-FSP 77 & $4.2 \pm 0.9$ \\
PS 2 & $24.0 \pm 2.1$ \\
PS 2-35A7 & $10.0 \pm 3.0$ \\
PS 2-FSP 77 & $1.7 \pm 1.1$ \\
\hline
\end{tabular}

$\mathrm{MAb}=$ monoclonal antibodies; $\mathrm{PS}=$ photosensitisers. Values expressed as the mean \pm s.d. of three experiments.

Table 3 MAb-PS conjugate DOL at differing initial molar ratios

\begin{tabular}{lccccc}
\hline & \multicolumn{2}{c}{ MAb 35A7 } & & \multicolumn{2}{c}{ MAb FSP 77 } \\
\cline { 2 - 3 } \cline { 5 - 6 } & \multicolumn{3}{c}{ DOL } \\
\cline { 2 - 5 } Initial molar ratio & PS I & PS 2 & PS I & PS 2 \\
\hline 20 & 1.4 & 1.6 & 2.8 & 1.6 \\
40 & 1.6 & 2.3 & 2.3 & 2.0 \\
60 & 2.0 & 2.5 & 1.6 & 2.0 \\
\hline
\end{tabular}

$\mathrm{MAb}=$ monoclonal antibodies; $\mathrm{DOL}=$ degree of labeling; $\% \mathrm{IDg}^{-1}=$ percent of injected dose per gram of tissue; $P S=$ photosensitisers.

of increasing the porphyrin loading of the MAb was examined to see if more potent derivatives could be constructed. The conjugates were then characterised further in an in vivo biodistribution study. Since limited quantities of MAb 17.1A were available and MAb FSP 77 represents an $\mathrm{MAb}$ that binds to an internalising receptor, the study was completed using only MAb 35A7 and FSP 77. To allow for comparative biodistribution studies using the MAb conjugates and unconjugated antibody, the antibodies were radiolabelled with either ${ }^{125} \mathrm{I}$ (conjugates) or ${ }^{131} \mathrm{I}$ (unconjugated antibodies). Repeat conjugations were performed using initial molar ratios of 20,40 and 60 and the conjugates were purified as before. The overall DOL of the antibodies with the photosensitisers was measured spectroscopically and is presented in Table 3.

Increasing the initial molar ratio generally led to minor increases in the DOL of the conjugates with photosensitiser. However, the DOL of the PS 1-FSP 77 conjugate decreased as the initial molar ratio increased. This was thought to be a consequence of the photosensitiser diminishing the solubility of the MAb in PBS at higher loading ratios. This also corresponded to a reduced recovery of the conjugate from the Sephadex G25 column, an effect that has been reported elsewhere (Vrouenraets et al, 2000). The conjugates synthesised using PS 2 and MAb 35A7 were recovered quantitatively. Clearly, when conjugating PS 1 with MAb FSP 77 at initial molar ratios of 40 and 60 , only the least substituted MAb is soluble enough to pass through the column.
The immunoreactivity of the conjugates in vitro was compared to that of the unconjugated antibodies in a direct binding assay using CEA and erb-B2 immobilised on sepharose. An irrelevant antigen $(\mathrm{Px})$ was used to assay any nonspecific binding. The conjugate binding to the respective antigens was not statistically different to that of the unconjugated antibodies (data not shown) and the nonspecific binding was less than $5 \%$ in each case.

\section{In vivo biodistribution}

For biodistribution analysis of the ${ }^{131} \mathrm{I}-\mathrm{MAb} 35 \mathrm{~A} 7$ and ${ }^{125} \mathrm{I}-\mathrm{MAb}$ $35 \mathrm{~A} 7$ - porphyrin conjugates, the LS174T cell line was subcutaneously implanted into the hind legs of Swiss nude mice. To assay the biodistribution of the ${ }^{125} \mathrm{I}-\mathrm{MAb}$ FSP 77 conjugates and ${ }^{131} \mathrm{I}$ labelled free antibody, SKOv3 cells were injected into the hindquarters of the same animal model. The biodistribution of the conjugates of each photosensitiser at differing degrees of labelling was compared to that of the unconjugated antibody for each conjugate subset. Figure 3 shows the biodistribution profile for the PS 1-35A7 conjugate at different DOL. The biodistribution of each conjugate was compared to the unconjugated antibody in each experiment. The $\% \mathrm{ID} \mathrm{g}^{-1}$ tumour and tumour-to-normal tissue ratios for representative peritumoral tissues for all the conjugates at each DOL are shown in Tables 4 and 5. The conjugates prepared using PS 1 have tumour uptake values comparable to those of the unconjugated MAb 35A7 (Figure 3) and FSP 77. Increasing the DOL of the conjugates using PS 2 is associated with a decreased uptake in tumour, in comparison to the unconjugated MAb. For example, using PS 2-35A7 conjugates with DOL of 1.6, 2.3 and 2.5 gave tumour uptake values of 23.9, 17.4 and $12.9 \% \mathrm{ID} \mathrm{g}^{-1}$ tissue, respectively.

Concurrent with biodistribution studies using a similar photosensitiser (Vrouenraets et al, 2000), it is evident that increased loading with PS 2 decreases the residence time of the MAb in the blood, resulting in reduced tumour uptake. The tumour-to-normal tissue ratios for the MAb 35A7 conjugates are significantly higher than those observed using the MAb FSP 77 conjugates. The tumour/blood ratios for the MAb 35A7 conjugate are moderate but similar to values reported elsewhere (Carcenac et al, 1999). The values for the MAb FSP 77 conjugates are slightly lower. This may reflect an increased MAb to tumour transport time using this antibody. Overall, the ratios for both antibody conjugates were still significantly higher than typical ratios reported using common photosensitisers (Boyle and Dolphin, 1996). Tumour-to-colon ratios for the PS 1-35A7 (DOL, 2.0) and PS 2-35A7 (DOL, 1.6) conjugates were 33.3 and 33.5 , respectively. Since the conjugates are directed against CEA, which is overexpressed on colorectal cancers in comparison to that on normal tissues, these values suggest the potential for more selective photosensitiser delivery to this tumour type.

\section{DISCUSSION}

The use of MAb to increase the specificity of photosensitisers for malignant tissues was first reported by Mew et al (1983). Alternative methods of conjugating to MAb using better defined photosensitisers and polymeric carriers were subsequently developed (Jiang et al, 1990; Goff et al, 1991). However, these conjugate preparations often contained significant amounts of impurities. A more refined method for conjugation to polymeric cationic and anionic carriers was later developed by Hamblin et al (1996) and was used successfully in vitro (Del Governatore et al, 2000) and in vivo (Duska et al, 1997). Within these studies, a chlorin e6-NHS ester is used without purification prior to attachment to the macromolecule. Also polycationic macromolecules can increase the rate of nonspecific cell-mediated endocytosis (Shen and Ryser, 1978). Other methodologies, also relying on activated ester groups, 


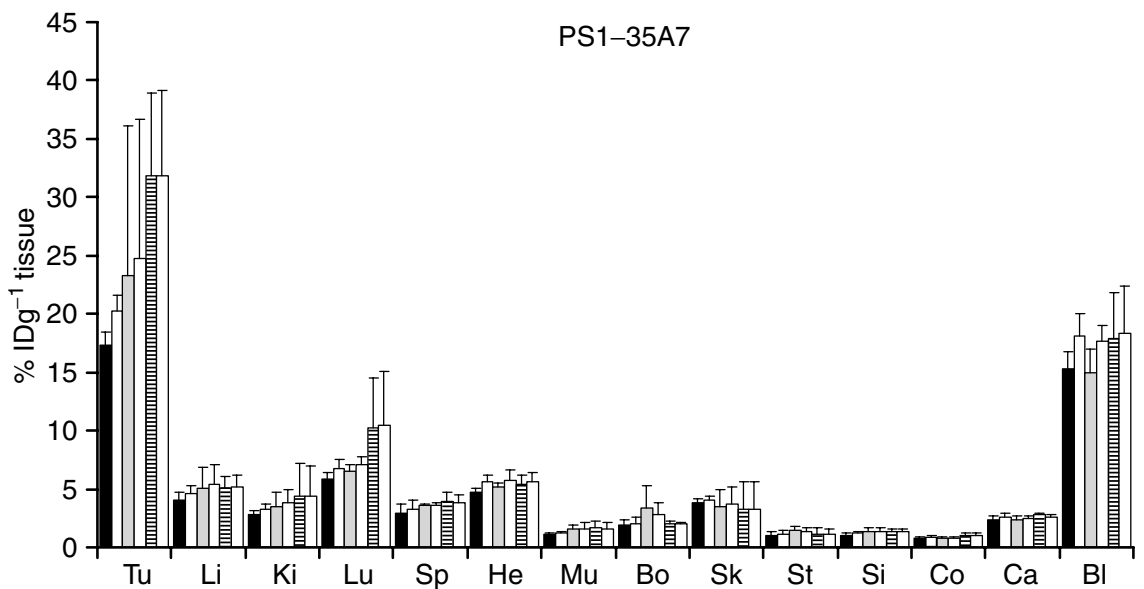

Figure 3 Biodistribution of unconjugated MAb control (open bars) and PS I -35A7 conjugate at the following DOL: I.4 (black bars), I.6 (grey bars), 2.0 (crossed bars). Tu, tumour; Li, liver; Ki, kidney; Lu, lungs; Sp, spleen; He, heart; Mu, muscle; Bo, bone; Sk, skin; St, stomach; Si, small intestine; Co, colon; Ca, carcass; Bl, blood. The values were obtained $24 \mathrm{~h}$ postinjection. Values are expressed as the mean \pm s.d. calculated from the three mice bearing the LSI $74 T$ xenograft in each conjugate group. The conjugates were compared to unconjugated MAb in three separate experiments.

Table $4 \% \mathrm{ID} \mathrm{g}^{-1}$ of tumour and tumour/normal tissue ratios for MAb 35A7 conjugates

\begin{tabular}{|c|c|c|c|c|c|}
\hline Conjugate+DOL & $\%$ ID g $^{-1}$ tumour & \multicolumn{4}{|c|}{ Ratio } \\
\hline PS I (1.6) & $23.3 \pm 12.8$ & $1.5 \pm 0.7$ & $16.8 \pm 10.0$ & $29.4 \pm 15.9$ & $18.8 \pm 12.3$ \\
\hline PS I (2.0) & $31.8 \pm \pm 7.0$ & $1.8 \pm 0.1$ & $18.5 \pm 2.8$ & $33.3 \pm 5.0$ & $23.0 \pm 3.2$ \\
\hline PS 2 (I.6) & $23.9 \pm 3.4$ & $2.1 \pm 0.2$ & $24.9 \pm 3.4$ & $33.5 \pm 3.8$ & $26.3 \pm 5.2$ \\
\hline PS 2 (2.3) & $17.4 \pm 6.2$ & $1.9 \pm 0.7$ & $19.8 \pm 6.0$ & $25.1 \pm 10.3$ & $14.8 \pm 12.2$ \\
\hline
\end{tabular}

$\% \mathrm{ID} \mathrm{g}^{-1}=$ percent of injected dose per gram of tissue; $\mathrm{MAb}=$ monoclonal antibodies; $\mathrm{DOL}=$ degree of labeling; $\mathrm{PS}=$ photosensitisers. Values were obtained $24 \mathrm{~h}$ postinjection (values are the means of tumour/normal ratios and $\% \mathrm{ID} \mathrm{g}^{-1}$ tumour \pm s.d. calculated from the three mice bearing the LSI74T xenograft in each conjugate group).

Table $5 \% \mathrm{ID}^{-1}$ of tumour and tumour/normal tissue ratios for MAb FSP 77 conjugates

\begin{tabular}{|c|c|c|c|c|c|}
\hline Conjugate+DOL & $\% I^{\prime D g} g^{-1}$ tumour & \multicolumn{4}{|c|}{ Ratio } \\
\hline PS I (2.3) & $7.4 \pm 2.2$ & $0.6 \pm 0.2$ & $5.6 \pm 0.2$ & $10.6 \pm 2.7$ & $5.3 \pm 2.2$ \\
\hline PS I (1.6) & $6.8 \pm 0.2$ & $0.9 \pm 0.7$ & $3.35 \pm 2.8$ & $7.5 \pm 0.3$ & $3.75 \pm 2.2$ \\
\hline PS 2 (1.6) & $8.5 \pm 2.1$ & $1.06 \pm 0.1$ & $9.2 \pm 6.3$ & $13.8 \pm 8.7$ & $10.7 \pm 6.4$ \\
\hline PS 2 (2.0) & $5.3 \pm 0.2$ & $0.6 \pm 0.2$ & $5.2 \pm 0.5$ & $8.6 \pm 4.1$ & $5.6 \pm 0.9$ \\
\hline
\end{tabular}

$\% \mathrm{ID}^{-1}=$ percent of injected dose per gram of tissue; $\mathrm{MAb}=$ monoclonal antibodies; $\mathrm{DOL}=$ degree of labeling; $\mathrm{PS}=$ photosensitisers. Values were obtained $24 \mathrm{~h}$ postinjection (values are the means of tumour/normal ratios and $\% \mathrm{IDg}^{-1}$ tumour \pm s.d. calculated from the three mice bearing the SKOv3 xenograft in each conjugate group).

have involved direct attachment of the photosensitiser to the MAb (Vrouenraets et al, 1999, 2001). The photosensitisers $m$-THPC and $[\mathrm{AlPc}(\mathrm{SO} 3 \mathrm{H})]_{4}$ with a trifluorophenyl (TFP)-ester group were obtained by hydrolysis of the corresponding tetra-TFP-ester intermediates. However, the procedure led to preparations containing appreciable amounts of fully hydrolysed by product. Savellano and Hasan (2003) later developed a purified monofunctionalised BPD-MA derivative and used a 50\% DMSO/50\% water system for conjugation. This procedure yielded wellcharacterised conjugates, although the solvent system is unlikely to be universally tolerated by MAb.

In the present study, we have investigated the use of photosensitiser isothiocyanates for conjugation to MAb. The photosensitisers were synthesised according to a previously published method (Clarke and Boyle, 1999). This synthesis yields pure photosensitiser, which unambiguously presents a single amino reactive group. Efficient conjugation to BSA, with negligible non-specific binding, has been previously demonstrated (Sutton et al, 2002). In a continuation of the study, the photosensitisers were conjugated with MAb 35A7, FSP 77 and 17.1A. Conjugations were performed under ambient conditions and the procedure allowed direct attachment of the photosensitisers to the MAb, with no prior modification of the antibodies. In this context, the isothiocyanate group represents a superior functionality for conjugation of photosensitisers to MAb. Retention of antigen binding was demonstrated using flow cytometry. The in vitro photoinduced cell inhibition of the conjugates was compared to the unconjugated photosensitisers. Conjugation to MAb 17.1A led 
to a significant decrease in the concentration of photosensitiser required for growth inhibition of the Colo 320 cell line as compared with free photosensitiser. Comparative analysis of the non-internalising 35A7 conjugates and the internalising FSP 77 conjugates was performed using the SKOv3-CEA-1B9 cell line. The non-internalising conjugates using MAb 35A7 were generally more effective than the free photosensitiser and the internalising MAb FSP 77 conjugates were significantly more active than the $35 \mathrm{~A} 7$ conjugates or the free photosensitiser. The PS 1-FSP 77 conjugate gave an $\mathrm{IC}_{50}$ value 16 times less than that of the unconjugated photosensitiser. Concurrent with results from previous studies (Carcenac et al, 2001), the use of internalising MAb in PIT offers advantages over conjugates of non-internalising $\mathrm{MAb}$ or free photosensitisers.

Radiolabelled conjugates were then prepared for use in in vivo biodistribution studies. MAb 35A7 and FSP 77 were chosen to represent $\mathrm{MAb}$ that are non-internalising and internalising, respectively. The biodistribution of the ${ }^{12}$ I-labelled conjugates was then compared to that of the ${ }^{131}$ I-labelled MAb in Swiss nude mice subcutaneously implanted with the appropriate antigenexpressing cell lines. The MAb conjugates with PS 1 had biodistribution values comparable to the unconjugated antibodies. A high uptake in the blood was observed with MAb FSP 77. The least substituted conjugates of PS 2 and the two MAb had tumour uptake values similar to the unconjugated antibodies. When the substitution of the MAb with the photosensitiser increased, the uptake in the tumour and other organs decreased significantly. This is consistent with a report by Pardridge et al (1998) who found that increasing an MAb cationic charge reduced its serum half-life to $5 \%$ of that of the unmodified antibody. The data from the biodistribution studies clearly demonstrates retention of MAb pharmacokinetics following substitution with PS 1 and to a lesser degree with PS 2. The observed tumour/normal tissue ratios using representative surrounding tissue for colon carcinomas were exceptionally high at 33.5 for the MAb 35A7 PS 2 conjugate. Tumour/normal tissue ratios between 2 and 4 have previously been reported for unconjugated photosensitisers (Boyle and Dolphin, 1996). Indeed, if tumour/normal tissue ratios could be significantly improved, PDT may play an important role in destroying early stage metastasis after surgical resection of large tumour masses. In conclusion, we have developed a convenient and widely applicable strategy for the conjugation of photosensitisers to antibodies that offers several advantages over methods currently employed for conjugation. The conjugates retained antigen binding and had pharmacokinetics comparable to the unconjugated antibodies. The use of conjugates of internalising antibodies offered clear advantages over free photosensitisers in PIT studies in vitro, in terms of both specificity and cytotoxicity, and hold promise for clinical use. Experiments assessing the phototoxicity of the conjugates in vivo are currently underway in our laboratories.

\section{ACKNOWLEDGEMENTS}

We wish to thank the Wellcome Trust (059572, 066948), BBSRC (21/E12509) and The Leverhume Trust $(\mathrm{F} / 00181 \mathrm{H})$ for financial support. RH thanks EPSRC for a studentship. The authors wish to thank Huguette Savoie for expert technical assistance.

\section{REFERENCES}

Biel MA (1998) Photodynamic therapy and the treatment of head and neck neoplasia. Laryngoscope 108: 1259-1267

Boyle RW, Dolphin D (1996) Structure and biodistribution relationships of photodynamic sensitizers. Photochem Photobiol 64: 469-485

Brasseur N, Langlois R, Madeleine CL, Ouellet R, van Lier JE (1999) Receptor-mediated targeting of phthalocyanines to macrophages via covalent coupling to native or maleylated bovine serum albumin. Photochem Photobiol 69: 345-352

Carcenac M, Dorvillius M, Garambois V, Glaussel F, Larroque C, Langlois R, Hynes NE, van Lier JE, Pelegrin A (2001) Internalisation enhances photo-induced cytotoxicity of monoclonal antibody-phthalocyanine conjugates. $\mathrm{Br}$ J Cancer 85: 1787-1793

Carcenac M, Larroque C, Langlois R, van Lier JE, Artus J-C, Pelegrin A (1999) Preparation, phototoxicity and biodistribution studies of anticarcinoembryonic antigen monoclonal antibody-phthalocyanine. Photochem Photobiol 70: $930-936$

Clarke OJ, Boyle RW (1999) Isothiocyanatoporphyrins, useful intermediates for the conjugation of porphyrins with biomolecules and solid supports. Chem Commun 2231-2232

Cuello M, Ettenberg SA, Clark AS, Keane MM, Posner RH, Nau MM, Dennis PA, Lipkowitz S (2001) Down-regulation of the erbB-2 Receptor by trastuzumab (Herceptin) enhances tumor necrosis factor-related apoptosis-inducing ligand-mediated apoptosis in breast and ovarian cancer cell lines that overexpress erbB-2. Cancer Res 61: $4892-4900$

Dougherty TJ, Gomer CJ, Henderson BW, Jori G, Kessel D, Korbelik M, Moan J, Peng Q (1998) Photodynamic therapy. J Natl Cancer Inst 90: 889-905

Duska LR, Hamblin MR, Bamberg MP (1997) Biodistribution of charged $\mathrm{F}\left(\mathrm{ab}^{\prime}\right)_{2}$ photoimmunoconjugates in a xenograft model of ovarian cancer. Br J Cancer 75: $837-844$

Gijsens A, Missiaen L, Merlevede W, de Witte P (2000) Epidermal growth factor-mediated targeting of chlorin $\mathrm{e}_{6}$ selectively potentiates its photodynamic activity. Cancer Res 60: 2197-2202

Goff BA, Bamberg M, Hasan T (1991) Photoimmunotherapy of human ovarian carcinoma cells ex vivo. Cancer Res 51: $4762-4767$

Del Governatore M, Hamblin MR, Piccinini EE, Ugolini G, Hasan T (2000) Targeted photodestruction of human colon cancer cells using charged 17.1A chlorin $\mathrm{e}_{6}$ conjugates. $\mathrm{Br} \mathrm{J}$ Cancer 82: 56-64
Hamblin MR, Del Governatore M, Rizvi I, Hasan T (2000) Biodistribution of charged 17.1A photoimmunoconjugates in a murine model of hepatic metastasis of colorectal cancer. Br J Cancer 83: $1544-1551$

Hamblin MR, Miller JL, Hasan T (1996) Effect of charge on the interaction of site-specific photoimmunoconjugates with human ovarian cancer cells. Cancer Res 56: $5205-5210$

Jiang FN, Jiang S, Liu D, Richter A, Levy JG (1990) Development of technology for linking photosensitizers to a model monoclonal antibody. J Immunol Methods 134: 139-149

Khare PD, Shao-Xi L, Kuroki M, Hirose Y, Arakawa F, Nakamura K, Tomita Y, Kuroki M (2001) Specifically targeted killing of carcinoembryonic antigen (CEA)-expressing cells by a retroviral vector displaying singlechain variable fragmented antibody to CEA and carrying the gene for inducible nitric oxide synthase. Cancer Res 61: 370-375

Kubler AC, Haase T, Staff C, Kahle B, Rheinwald M, Muhling J (1999) Photodynamic therapy of primary nonmelanomatous skin tumours of the head and neck. Lasers Surg Med 25: 60-68

Macdonald IJ, Dougherty TJ (2001) Basic Principles of Photodynamic Therapy. J Porphyrins Phthalocyanines 5: 105-129

Mew D, Wat CK, Towers GHN, Levy JG (1983) Photoimmunotherapy: treatment of animal tumours with tumour-specific monoclonal antibody-hematoporphyrin conjugates. J Immunol 130: 1473 - 1477

Nseyo UO, Shumaker B, Klein EA, Sutherland K (1998) Photodynamic therapy using porfimer sodium as an alternative to cystectomy in patients with refractory transitional cell carcinoma in situ of the bladder. J Urol 160: $39-44$

Pardridge WM, Buciak J, Yang J, Wu D (1998) Enhanced endocytosis in cultured human breast carcinoma cells and in vivo biodistribution in rats of a humanized monoclonal antibody after cationization of the protein. J Pharmacol Exp Ther 286: 548 - 554

Savellano MD, Hasan T (2003) Targeting cells that overexpress the epidermal growth factor receptor with polyethylene glycolated BPD verteporfin photosensitizer immunoconjugates. Photochem Photobiol 77: $431-439$

Shen WC, Ryser HJ (1978) Conjugation of poly-L-lysine to albumin and horse radish peroxidase: a novel method of enhancing the cellular uptake of proteins. Acad Sci USA 75: $1872-1876$ 
Sutton JM, Clarke OJ, Fernandez N, Boyle RW (2002) Porphyrin, chlorin, and bacteriochlorin isothiocyanates: useful reagents for the synthesis of photoactive bioconjugates. Bioconjugate Chem 13: $249-263$

Swamy N, James DA, Mohr SC, Hanson RN, Ray R (2002) An estradiolporphyrin conjugate selectively localizes into estrogen receptor-positive breast cancer cells. Bioorg Med Chem 10: 3237-3243

Vrouenraets MB, Visser GWM, Loup C, Meunier B, Stigter M, Oppelaar H, Stewart FA, Snow GB, van Dongen GAMS (2000) Targeting of a hydrophilic photosensitizer by use of internalizing monoclonal anti- bodies: a new possibility for use in photodynamic therapy. Int J Cancer 88: $108-114$

Vrouenraets MB, Visser GWM, Stewart FA, Stigter M, Oppelaar H, Postmus PE, Snow GB, van Dongen GAMS (1999) Development of metatetrahydroxyphenylchlorin-monoclonal antibody conjugates for photoimmunotherapy. Cancer Res 59: $1505-1513$

Vrouenraets MB, Visser GWM, Stigter M, Oppelaar H, Snow GB, van Dongen GAMS (2001) Targeting of aluminium (III) phthalocyanine tetrasulfonate by use of internalizing monoclonal antibodies: improved efficacy in photodynamic therapy. Cancer Res 61: 1970-1975 